\title{
Luteolin triggers global changes in the microglial transcriptome leading to a unique anti- inflammatory and neuroprotective phenotype
}

\author{
Konstantin Dirscherl ${ }^{1 \dagger}$, Marcus Karlstetter $^{1 \dagger}$, Stefanie Ebert ${ }^{1 \dagger}$, Dominik Kraus ${ }^{1}$, Julia Hlawatsch ${ }^{1}$, Yana Walczak',
} Christoph Moehle ${ }^{2}$, Rudolf Fuchshofer ${ }^{3}$, Thomas Langmann ${ }^{1 *}$

\begin{abstract}
Background: Luteolin, a plant derived flavonoid, exerts a variety of pharmacological activities and anti-oxidant properties associated with its capacity to scavenge oxygen and nitrogen species. Luteolin also shows potent antiinflammatory activities by inhibiting nuclear factor kappa B (NFkB) signaling in immune cells. To better understand the immuno-modulatory effects of this important flavonoid, we performed a genome-wide expression analysis in pro-inflammatory challenged microglia treated with luteolin and conducted a phenotypic and functional characterization.
\end{abstract}

Methods: Resting and LPS-activated BV-2 microglia were treated with luteolin in various concentrations and mRNA levels of pro-inflammatory markers were determined. DNA microarray experiments and bioinformatic data mining were performed to capture global transcriptomic changes following luteolin stimulation of microglia. Extensive qRT-PCR analyses were carried out for an independent confirmation of newly identified luteolin-regulated transcripts. The activation state of luteolin-treated microglia was assessed by morphological characterization. Microglia-mediated neurotoxicity was assessed by quantifying secreted nitric oxide levels and apoptosis of 661W photoreceptors cultured in microglia-conditioned medium.

Results: Luteolin dose-dependently suppressed pro-inflammatory marker expression in LPS-activated microglia and triggered global changes in the microglial transcriptome with more than 50 differentially expressed transcripts. Proinflammatory and pro-apoptotic gene expression was effectively blocked by luteolin. In contrast, mRNA levels of genes related to anti-oxidant metabolism, phagocytic uptake, ramification, and chemotaxis were significantly induced. Luteolin treatment had a major effect on microglial morphology leading to ramification of formerly amoeboid cells associated with the formation of long filopodia. When co-incubated with luteolin, LPS-activated microglia showed strongly reduced NO secretion and significantly decreased neurotoxicity on 661W photoreceptor cultures.

Conclusions: Our findings confirm the inhibitory effects of luteolin on pro-inflammatory cytokine expression in microglia. Moreover, our transcriptomic data suggest that this flavonoid is a potent modulator of microglial activation and affects several signaling pathways leading to a unique phenotype with anti-inflammatory, antioxidative, and neuroprotective characteristics. With the identification of several novel luteolin-regulated genes, our findings provide a molecular basis to understand the versatile effects of luteolin on microglial homeostasis. The data also suggest that luteolin could be a promising candidate to develop immuno-modulatory and neuroprotective therapies for the treatment of neurodegenerative disorders.

\footnotetext{
* Correspondence: thomas.langmann@klinik.uni-regensburg.de

† Contributed equally

${ }^{1}$ Institute of Human Genetics, University of Regensburg, Franz-Josef-Strauss-

Allee 11, 93053 Regensburg, Germany
} 


\section{Background}

Microglia, the resident macrophages of the nervous system, have important roles in immune regulation $[1,2]$ and neuronal homeostasis [3,4]. Microglia belong to the mononuclear phagocyte system but their special localization in the fragile neuronal environment and their morphological features clearly distinguish them from other peripheral macrophages [5]. Ramified microglia perform a very active and continous surveillance function with their long protrusions $[6,7]$. They receive permanent tonic inhibitory inputs from neurons to prevent microglial neurotoxicity $[8,9]$. Loss of microglia-neuron cross-talk [10], local danger signals such as extracellular ATP [11], or neurotransmitter gradients [12] rapidly lead to a functional transformation of ramified microglia with a variety of effector functions.

Microglia activation is a protective mechanism regulating tissue repair and recovery in the early phase of neurodegeneration [4]. However, excessive or sustained activation of microglia often contributes to acute and chronic neuro-inflammatory responses in the brain and the retina [2]. Activated microglia in the vicinity of degenerating neurons have been identified in a broad spectrum of neurodegenerative disorders including Alzheimer's disease [13], Parkinson's disease [14], amyotrophic lateral sclerosis [15], multiple sclerosis [16], and inherited photoreceptor dystrophies $[17,18]$.

Macrophage heterogeneity and plasticity is very large and the set of marker combinations and sub-populations is essentially infinite [19]. To define a simplified conceptual framework, classification into polarized functional categories, called M1 and M2 macrophages has been proposed [20,21]. M1 or "classically activated" macrophages produce high levels of oxidative metabolites and pro-inflammatory cytokines but also cause damage to healthy tissue as side effect [22]. M2 or "alternatively activated" macrophages promote tissue remodeling and generally suppress destructive immune reactions. Informations on microglial subsets in the nervous system are relatively scarce compared to other tissue macrophages. Nevertheless, recent findings from in vitro cultures of the murine microglial cell line MMGT12 [23] and hippocampal microglia from the PS1xAPP Alzheimer's mouse model [24] implicate that microglia have the ability to differentiate into M1 and M2 polarized phenotypes. A co-existence of neurotoxic M1 microglia and regenerative $\mathrm{M} 2$ microglia has been recently documented in the injured mouse spinal cord [25]. Microarraybased quantitation of M1 and M2 markers as well as functional tests on axonal regrowth after injury demonstrated that a transient anti-inflammatory and neuroprotective M2 response was rapidly overwhelmed by a neurotoxic M1 microglial response [25]. A similar but age-dependent switch from alternative to classical activation was shown in PS1xAPP Alzheimer's mice [24], indicating a common phenomenon in neurodegenerative disorders. Compounds that induce the switch of microglia from inflammatory M1 type to anti-inflammatory M2 type could therefore be a potential therapeutic agent to attenuate neuronal inflammation and boost neuronal recovery [26].

Several anti-inflammatory drugs have been shown to diminish neuroinflammation, but only a few direct functional effects on microglial activity have been elucidated [27]. Among the naturally occuring immuno-modulators, the flavonoid luteolin $\left(3^{\prime}, 4,5,7\right.$-tetrahydroxyflavone), abundant in parsley, green pepper, celery, perilla leaf, and chamomile tea, exerts prominent anti-inflammatory and anti-oxidant activities [28]. Luteolin suppressed pro-inflammatory cytokine production in macrophages by blocking nuclear factor kappa B (NFkB) and activator protein 1 (AP1) signaling pathways [29] and inhibited the production of nitric oxide [30] and pro-inflammatory eicosanoids [31]. Luteolin also diminshed the release of Tnf and superoxide anions in LPS or interferon- $\gamma$ treated microglial cell cultures $[32,33]$ and reduced the LPS-induced 116 production in brain microglia in vivo [34].

Although the inhibitory function of luteolin on NFkB and a few selected cytokines is well documented in macrophages, a genome-wide search for further molecular targets in microglia has not yet been published. Furthermore, the immuno-modulatory effects of luteolin related to the stimulation of distinct functional microglial phenotypes has not been investigated before. Therefore, this study investigated the global transcriptomic effects of luteolin at near physiological concentrations [35] alone or in combination with LPS in pure BV-2 microglial cultures. We further validated the luteolin-regulated expression of novel pro- and anti-inflammtory microglial transcripts, analyzed microglial morphology, and studied the consequences of microgliaconditioned media for photoreceptor viability.

\section{Methods}

Reagents

Luteolin (3',4',5,7-tetrahydroxyflavone) and E. coli 0111: B4 lipopolysaccharide were purchased from Sigma Aldrich (Steinheim, Germany). Luteolin was dissolved in DMSO and added in concentrations that did not exceed $0.05 \%$ of the total volume in any of the cell culture experiments.

\section{Animals}

C57BL/6 mice were purchased from Charles River Laboratories. Mice were kept in an air-conditioned barrier environment at constant temperature of $20-22^{\circ} \mathrm{C}$ on 
a 12-h light-dark schedule, and had free access to food and water. The health of the animals was regularly monitored, and all procedures were approved by the University of Regensburg animal rights committee and complied with the German Law on Animal Protection and the Institute for Laboratory Animal Research Guide for the Care and Use of Laboratory Animals, 1999.

\section{Cell culture}

Brain microglia were isolated and cultured as described earlier [36]. BV-2 microglia-like cells were provided by Professor Ralph Lucius (Clinic of Neurology, Christian Albrechts University, Kiel, Germany). BV-2 cells were cultured in RPMI/5\% FCS supplemented with $2 \mathrm{mM} \mathrm{L-}$ Glutamine and $195 \mathrm{nM} \beta$-mercaptoethanol. Primary brain microglia or BV-2 cells were stimulated with 10 $\mathrm{ng} / \mathrm{ml}$ or $50 \mathrm{ng} / \mathrm{ml}$ LPS and various concentrations of luteolin for $24 \mathrm{~h}$. $661 \mathrm{~W}$ photoreceptor-like cells were a gift from Prof. Muayyad Al-Ubaidi (University of Illinois, Chicago, IL) and the culture conditions have been described elsewhere [36].

\section{Phalloidin staining}

BV-2 cells were plated overnight on coverslips, fixed with $3.7 \%$ paraformaldehyde for $10 \mathrm{~min}$ at $37^{\circ} \mathrm{C}$, permeabilized with $0.2 \%$ Triton $\mathrm{X}-100$ for $5 \mathrm{~min}$, blocked with $5 \%$ non-fat milk, $0.2 \%$ Triton X-100, and stained with DAPI for $10 \mathrm{~min}$ at room temperature $(0.1 \mu \mathrm{g} / \mathrm{ml}$ in PBS, 4',6-diamidino-2-phenylindol, Molecular Probes). Filamentous actin was stained by addition of $1.5 \mu \mathrm{M}$ TRITC-conjugated phalloidin (Sigma). The coverslips were mounted on microscopic glass slides and viewed with a Axioskop 2 fluorescence microscope equipped with an Eclipse digital analyzer (Carl Zeiss).

\section{NO measurement}

NO concentrations were determined by measuring the amount of nitrite secreted by BV-2 cells into the culture medium using the Griess reagent system (Promega). 50 $\mu \mathrm{l}$ cell culture supernatant was collected and an equal volume of Griess reagent was added to each well. After incubation for $15 \mathrm{~min}$ at room temperature, the absorbance was read at $540 \mathrm{~nm}$ on a BMG FluoStar Optima plate reader (Labtech, Offenburg, Germany). The concentration of nitrite for each sample was calculated from a sodium nitrite standard curve.

\section{Apoptosis assay}

Apoptotic cell death of $661 \mathrm{~W}$ cells was determined with the Caspase-Glo ${ }^{\circ}$ 3/7 Assay (Promega). Cells were lysed and incubated with a luminogenic caspase- $3 / 7$ substrate, which contains the tetrapeptide sequence DEVD. Luminescence was then generated by addition of recombinant luciferase and was proportional to the amount of caspase activity present. The luminescent signal was read on a BMG FluoStar Optima plate reader (Labtech, Offenburg, Germany). A blank reaction was used to measure background luminescence associated with the cell culture system and Caspase-Glo ${ }^{\circ}$ 3/7 Reagent. The value for the blank reaction was subtracted from all experimental values. Negative control reactions were performed to determine the basal caspase activity of $661 \mathrm{~W}$ cells.

\section{RNA isolation and reverse transcription}

Total RNA was extracted from cultured microglia according to the manufacturer's instructions using the RNeasy Protect Mini Kit (Qiagen, Hilden, Germany). Purity and integrity of the RNA was assessed on the Agilent 2100 bioanalyzer with the RNA 6000 Nano LabChip ${ }^{\circ}$ reagent set (Agilent Technologies, Büblingen, Germany). The RNA was quantified spectrophotometrically and then stored at $-80^{\circ} \mathrm{C}$. First-strand cDNA synthesis was performed with RevertAid ${ }^{m}$ H Minus First Strand cDNA Synthesis Kit (Fermentas, St. Leon-Rot, Germany).

\section{DNA microarray analysis}

Triplicate microarrays were carried out with three independent RNAs from non-stimulated BV-2 microglia or cultures treated for $24 \mathrm{~h}$ with $50 \mu \mathrm{M}$ luteolin, $50 \mathrm{ng} / \mathrm{ml}$ LPS, or $50 \mu \mathrm{M}$ LPS + $50 \mathrm{ng} / \mathrm{ml}$ LPS, respectively. Generation of double-stranded cDNA, preparation and labeling of cRNA, hybridization to Affymetrix 4302.0 mouse genome arrays, washing, and scanning were performed according to the Affymetrix standard protocol. Minimum information about a microarray experiment (MIAME) criteria were met [37]. The microarray datasets of this study are publicly available at the National Center for Biotechnology Information Gene Expression Omnibus http://www.ncbi.nlm.nih.gov/geo/ as series record GSE18740.

\section{Bioinformatic data analysis}

The Affymetrix Expression Console Software Version 1.0 was used to create summarized expression values (CHP-files) from 3' expression array feature intensities (CEL-files) using the Robust Multichip Analysis (RMA) algorithm. Integrative analysis of genome-wide expression activities from BV-2 cells was performed with the Gene Expression Dynamics Inspector (GEDI), a Matlab (Mathworks, Natick, MA) freeware program which uses self-organizing maps (SOMs) to translate high-dimensional data into a 2D mosaic [38]. Each tile of the mosaic represents an individual SOM cluster and is color-coded to represent high or low expression of the cluster's genes, thus identifying the underlying pattern.

Differentially regulated transcrips in $24 \mathrm{~h}$ luteolin stimulated versus non-treated and luteolin + LPS versus LPS-treated BV-2 cells, respectively, were retrieved with the Genomatix ChipInspector program (Genomatix Software GmbH, Munich, Germany), applying the Significance Analysis of Microarray (SAM) algorithm using a false-discovery rate of $0.1 \%$ and a minimum coverage of 3 independent probes. 
Functional annotation of transcripts was performed using the Database for Annotation, Visualization, and Integrated Discovery (DAVID) [39] and the Bibliosphere pathway edition (Genomatix).

\section{Quantitative real-time RT-PCR}

Amplifications of $50 \mathrm{ng}$ cDNA were performed with an ABI7900HT machine (Applied Biosystems) in triplicates in $10 \mu \mathrm{l}$ reaction mixtures containing $1 \times$ TaqMan Universal PCR Master Mix (Applied Biosystems), $200 \mathrm{nM}$ of primers and $0.25 \mu \mathrm{l}$ dual-labeled probe (Roche ProbeLibrary). The reaction parameters were as follows: 2 min $50^{\circ} \mathrm{C}$ hold, 30 -min $60^{\circ} \mathrm{C}$ hold, and 5 -min $95^{\circ} \mathrm{C}$ hold, followed by 45 cycles of 20 -s $94^{\circ} \mathrm{C}$ melt and 1 -min $60^{\circ} \mathrm{C}$ anneal/extension. Measurements were performed in triplicate. Results were analyzed with an ABI sequence detector software version 2.3 using the $\Delta \Delta C$ t method for relative quantitation. Primer sequences and Roche Library Probe numbers are listed in Table 1.

\section{Statistical analysis}

Statistical analysis were performed on $\Delta \Delta \mathrm{Ct}$ data using analysis of variance with a two-sample Student's t test $(\mathrm{P}<0.05)$ unless otherwise indicated. Quantitative data are expressed as mean \pm SEM. The levels of gene expression in treated BV-2 cells are shown relative to control cells.

\section{Results}

Effects of luteolin on selected pro-inflammatory markers As a basis to study the genome-wide transcriptional effects of luteolin on activated microglia and to validate our cell culture system, we initially performed a dose-response curve for luteolin. Four pro-inflammatory microglia

Table 1 Primer pairs and Roche library probes for real time qRT-PCR validation

\begin{tabular}{|c|c|c|c|}
\hline Gene & F-Primer $\left(5^{\prime}-3^{\prime}\right)$ & R-Primer $\left(5^{\prime}-3^{\prime}\right)$ & Roche Library Probe \\
\hline AA467197 & aaatggtggatcctactcaacc & gttgecctccggactttt & 17 \\
\hline Blvrb & tcctcggagttctcagcttt & gcaccgtcacctcataacct & 81 \\
\hline C3 & accttacctcggcaagtttct & ttgtagagctgctggtcagg & 76 \\
\hline CD36 & ttgaaaagtctcggacattgag & tcagatccgaacacagcgta & 6 \\
\hline CD83 & gctctcctatgcagtgtcctg & ggatcgtcagggaataggc & 2 \\
\hline $\mathrm{Cfb}$ & ctcgaacctgcagatccac & tcaaagtcctgcggtcgt & 1 \\
\hline Cst7 & atgtcagcaaagccctggta & ggtcttcctgcatgtagttcg & 67 \\
\hline Cxcl10 & gctgccgtcattttctgc & tctcactggeccgtcatc & 3 \\
\hline Ddit3 & ccaccacacctgaaagcag & tcctcataccaggettcca & 33 \\
\hline Gbp2 & tgtagaccaaaagttccagacaga & gataaaggcatctcgcttgg & 62 \\
\hline Gbp3 & aagattgagctgggctacca & gaaactcttgagaacctcttttgc & 73 \\
\hline Gclm & tggagcagctgtatcagtgg & caaaggcagtcaaatctggtg & 18 \\
\hline Gusb & gtgggcattgtgctacctg & atttttgtcccggcgaac & 25 \\
\hline Hmox1 & ctgctagcctggtgcaaga & ccaacaggaagctgagagtga & 25 \\
\hline $\mathrm{Hp}$ & ccctgggagctgttgtca & ctttgggcagctgtcatctt & 15 \\
\hline Hprt1 & tcctcctcagaccgctttt & cctggttcatcatcgctaatc & 95 \\
\hline Ifi44 & ctgattacaaaagaagacatgacagac & aggcaaaaccaaagactcca & 78 \\
\hline Ifitm3 & aacatgcccagagaggtgtc & accatcttccgatccctagac & 84 \\
\hline Ifitm6 & ccggatcacattacctggtc & catgtcgeccaccatctt & 27 \\
\hline IL-6 & gatggatgctaccaaactggat & ccaggtagctatggtactccaga & 6 \\
\hline iNos & ctttgccacggacgagac & tcattgtactctgagggctga & 13 \\
\hline Irf7 & cttcagcactttcttccgaga & tgtagtgtggtgacccttgc & 25 \\
\hline Kdr & cagtggtactggcagctagaag & acaagcatacgggcttgttt & 68 \\
\hline Len2 & atgtcacctccatcctggtc & cctgtgcatatttcccagagt & 1 \\
\hline Lpcat1 & aatgtgaggcgtgtcatgg & ggcagtcctcaaatgtatagtcg & 81 \\
\hline Marco & cagagggagagcacttagcag & gccccgacaattcacatt & 20 \\
\hline Mpeg1 & cacagtgagcctgcacttaca & gcgctttcccaatagcttta & 69 \\
\hline Nupr1-F & gatggaatcctggatgaatatga & gtccgacctttccgacct & 64 \\
\hline Rnf145 & catggacttctggcttctcat & aataaaaagtgttcccagaacctg & 67 \\
\hline Saa3 & atgctcgggggaactatgat & acagcctctctggcatcg & 26 \\
\hline Slpi & gtgaatcctgttcccattcg & cctgagttttgacgcacctc & 69 \\
\hline Srxn1 & gctatgccacacagagaccata & gtgggaaagctggtgtcct & 33 \\
\hline Trib3 & gctatcgagccctgcact & acatgctggtgggtaggc & 98 \\
\hline
\end{tabular}


markers with different expression levels and ranges of induction were selected as positive controls for qRT-PCR analyses. Interleukin 6 (Il6) is a well known pro-inflammatory cytokine target of luteolin [34], chemokine (C-X-C motif) ligand 10 (Cxcl10), interferon-regulatory factor 7 (Irf7), and interferon-inducible protein 44 (Ifi44) are LPSsensitive genes in microglia [36]. BV-2 microglia were pretreated with different concentrations of luteolin $(0,5,10$, 25 , and $50 \mu \mathrm{M})$ for $1 \mathrm{~h}$ and then stimulated with LPS (10 $\mathrm{ng} / \mathrm{ml}$ and $50 \mathrm{ng} / \mathrm{ml}$ ) for a further $24 \mathrm{~h}$ period. Neither LPS nor luteolin changed the proliferation rate or cell survival at the concentration levels applied to the cells (data not shown). mRNA levels of Il6 (Fig. 1A), Cxcl10 (Fig. 1B), Irf7 (Fig. 1C), and Ifi44 (Fig. 1D), which were all induced by $10 \mathrm{ng} / \mathrm{ml}$ LPS and further increased by $50 \mathrm{ng} / \mathrm{ml} \mathrm{LPS}$, were dose-dependently reduced by luteolin (Fig. 1A-D). Luteolin's effects on the four genes were most prominent at $50 \mu \mathrm{M}$ (Fig. 1A-D) and therefore this concentration was used in all further experiments.

\section{Luteolin triggers global changes in the microglial transcriptome}

Our next goal was to capture and compare the transcriptional profile of non-activated and LPS-activated BV-2 microgli treated each with $50 \mu \mathrm{M}$ luteolin for $24 \mathrm{~h}$ using Affymetrix Mouse Genome 4302.0 GeneChips. Twelve microarray analyses from three independent stimulation experiments were performed and high stringency criteria with a minimal signal intensity of 50 fluorescence units were used. The complete microarray RMA datasets and all raw data (Affymetrix CEL-files) were stored in the NCBI GEO repository as record GSE18740. We used the Gene Expression Dynamics Inspector (GEDI) to determine the global patterns of gene expression in the four different conditions, untreated, luteolin-treated, LPS-treated, and luteolin + LPS-treated microglia. GEDI is based on self-organizing maps to identify genome-wide transcriptome activity via 'gestalt' recognition [38]. GEDI is sample-oriented rather than gene-oriented, which facilitates the identification of genome-wide patterns. Each mosaic tile in the GEDI map represents a gene group or cluster that is expressed at similar levels, with blue color indicating a low level and red corresponding to high expression. The four GEDI maps clearly show a dynamic regulation of gene expression in stimulated versus nonstimulated microglia (Fig. 2). Especially the upper right positions in the control dataset and more pronounced in the LPS-treated dataset display an inverse regulation of the gene clusters following luteolin stimulation (Fig. 2A, white circles). These results demonstrate that stimulation with luteolin has a major impact on the global pattern of gene expression notably in activated microglia and to a lower extend in resting cells.
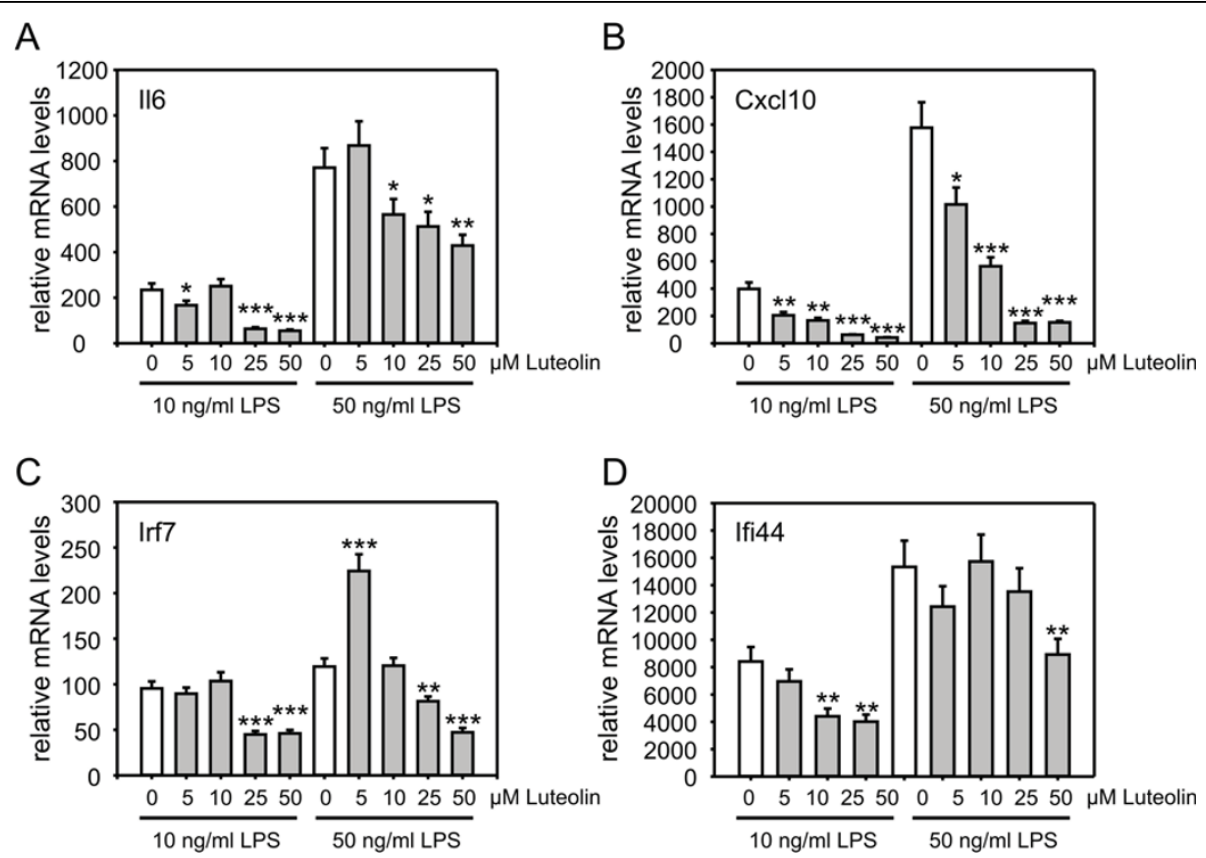

Figure 1 Dose-dependent suppression of LPS-induced pro-inflammatory gene expression in BV-2 microglia. BV-2 microglia were treated with the indicated concentrations of luteolin for $1 \mathrm{~h}$ and then stimulated with $10 \mathrm{ng} / \mathrm{ml}$ or $50 \mathrm{ng} / \mathrm{ml}$ LPS for $24 \mathrm{~h}$. Gene expression levels of (A) interleukin 6 (II6), (B) chemokine (C-X-C motif) ligand 10 (CxCl10), (C) interferon-regulatory factor 7 (Irf7), and (D) interferon-induced gene 44 (Ifi) were analyzed with real-time qRT-PCR. Expression was normalized to the control gene Gusb and mRNA levels (+/- SEM) are graphed relative to mock-treated control cells. Results are calculated from three independent experiments performed in triplicate measurements. ${ }^{*} p \leq 0.05,{ }^{* *} p \leq$ 0.01 , and ${ }^{* * *} p \leq 0.001$ for luteolin + LPS vs. LPS, respectively. 

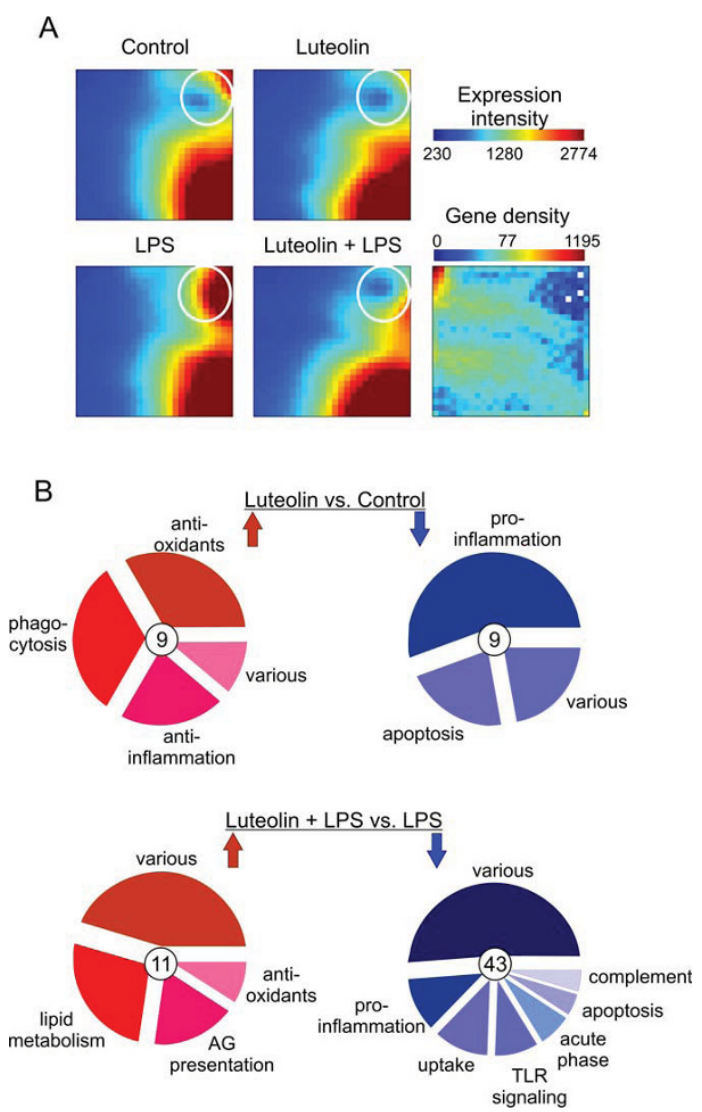

Figure 2 Luteolin triggers global transcriptomic changes in non-activated and LPS-activated BV-2 microglia. (A) Comparative Gene Expression Dynamics Inspector (GEDI) analysis of DNAmicroarray datasets from control BV-2 cells or cells treated with 50 $\mu \mathrm{M}$ luteolin, $50 \mathrm{ng} / \mathrm{ml}$ LPS, or $50 \mu \mathrm{M}$ luteolin $+50 \mathrm{ng} / \mathrm{ml}$ LPS. The white circle denotes the most prominent expression changes in several corresponding gene clusters. (B) Genomatix Chiplnspector single probe analysis of differentially expressed transcripts in luteolin versus control-treated cells (top) or luteolin + LPS treated cells versus LPS stimulated cells. Triplicate Affymetrix Mouse 4302.0 GeneChips were analyzed with a false-discovery-rate (FDR) $<0.1 \%, 3$ significant probes and $\log 2$ ratios $>1$. Differentially expressed transcrips from both comparisons were subjected to pathway analysis and clusters with $\geq 3$ genes were defined as an

independent group. Up-regulated genes are shown on the left side in red and down-regulated genes are displayed on the right side in blue. The total numbers of significantly up- or down-regulated genes from both comparions are indicated in circles placed in the centers of individual pie charts. All differentially expressed genes are listed in Tables 2 and 3, respectively.

We have previously shown that a single probe analysis of Affymetrix microarrays using the Genomatix ChipInspector tool with the Significance Analysis of Microarray (SAM) algorithm improves detection of regulated transcripts [40]. We therefore used ChipInspector to analyze our dataset applying a false discovery rate (FDR) of $0.1 \%$, a minimal probe coverage of 3 , and a minimum $\log 2$ ratio of 1 (fold change of 2.0). Thereby, 18 significantly regulated genes were identified in luteolintreated versus non-treated microglia (Table 2) and 54 differentially expressed genes were detected in luteolin + LPS versus LPS-stimulated cells (Table 3). Comparison of the total numer of differentially expressed genes indicated that the effects of luteolin were more pronounced in LPS-activated BV-2 cells than in resting microglia. Also, the overall fold change range was higher in the LPS-treated microglia than in the resting BV-2 cells when stimulated with luteolin. These finding correlate with the gene cluster patterns observed in GEDI analysis and implicate that luteolin is an effective counter-player of pro-inflammatory microglial activation.

Luteolin regulates important immune pathways and changes the microglial transcriptional phenotype

Our next aim was to put the newly identified luteolinregulated expression patterns into a specific biological context. We used all differentially expressed genes to perform a classification into functional categories with the Database for Annotation, Visualization, and Integrated Discovery (DAVID). The major enriched functional categories in luteolin-treated resting microglia were anti-oxidants, phagocytosis, and anti-inflammation for up-regulated genes and pro-inflammation and apoptosis for down-regulated genes (Fig. 2B, upper part). These pathways indicate that luteolin stimulated antioxidant and anti-inflammatory transcriptional programs which could potentially reflect M2 macrophage polarization. Moreover, basal pro-inflammatory and pro-apoptotic gene expression was blocked in non-activated BV-2 microglia. In luteolin + LPS co-treated versus LPS-treated cells, 11 induced transcripts represented pathways of lipid metabolism, antigen presentation, and anti-oxidants (Fig. 2B, bottom left). Interestingly, a large number of down-regulated genes covered the pathway categories pro-inflammation, toll-like receptor (TLR) signaling, acute phase response, apoptosis, and complement factors (Fig. 2B, bottom right). These results implicate that luteolin-induced transcriptomic changes promote a stable anti-inflammatory, anti-oxidant, and anti-apoptotic microglial phenotype reminescent of M2 macrophages. Our microarray data also identified a significant number of genes that could not be grouped into larger immune-related pathways and that have not been previously connected to microglial activation or flavonoid stimulation (Tables 2 and 3).

Microarray validation by qRT-PCR confirms novel luteolinregulated target genes

To validate a significant portion of the DNA microarray results, real-time qRT-PCR analyses were carried out with RNA samples from three independent BV-2 replicate experiments. We focused on representative candidates from different biological pathway which have not been previously described as flavonoid targets. 22 genes 
Table 2 Differentially expressed transcripts after 24 h stimulation of BV-2 cells with $50 \mu \mathrm{M}$ luteolin

\begin{tabular}{|c|c|c|c|c|c|}
\hline $\mathrm{Nr}$ & ID & Symbol & Gene Name & $\mathrm{FC}^{*}$ & Cov \\
\hline \multicolumn{6}{|c|}{ UP-REGULATED } \\
\hline 1 & 74315 & Rnf145 & Ring finger protein 145 & 2.87 & 11 \\
\hline 2 & 76650 & Srxn1 & Sulfiredoxin 1 homolog & 2.38 & 5 \\
\hline 3 & 19252 & Dusp1 & Dual specificity phosphatase 1 & 2.35 & 10 \\
\hline 4 & 12267 & C3ar1 & Complement component $3 a$ receptor 1 & 2.30 & 22 \\
\hline 5 & 12491 & $\mathrm{Cd} 36$ & CD36 antigen & 2.28 & 10 \\
\hline 6 & 12475 & Cd14 & CD14 antigen & 2.25 & 10 \\
\hline 7 & 233016 & Blvrb & Biliverdin reductase $B$ & 2.22 & 9 \\
\hline 8 & 15368 & Hmox1 & Heme oxygenase 1 & 2.17 & 10 \\
\hline 9 & 210992 & Lpcat1 & Lysophosphatidylcholine acyltransferase 1 & 2.13 & 11 \\
\hline \multicolumn{6}{|c|}{ DOWN-REGULATED } \\
\hline 1 & 13198 & Ddit3 & DNA-damage inducible transcript 3 & -5.21 & 11 \\
\hline 2 & 12862 & Cox6a2 & Cytochrome c oxidase, subunit VI a, polypeptide 2 & -2.89 & 9 \\
\hline 3 & 228775 & Trib3 & Tribbles homolog 3 & -2.62 & 22 \\
\hline 4 & 56312 & Nupr1 & Nuclear protein 1 & -2.36 & 15 \\
\hline 5 & 13011 & Cst7 & Cystatin F & -2.19 & 9 \\
\hline 6 & 223920 & Soat2 & Sterol O-acyltransferase 2 & -2.16 & 8 \\
\hline 7 & 16149 & $\mathrm{Cd} 74$ & CD74 antigen & -2.10 & 8 \\
\hline 8 & 17064 & $\operatorname{Cd} 93$ & CD93 antigen & -2.08 & 11 \\
\hline 9 & 213002 & Ifitm6 & Interferon induced transmembrane protein 6 & -2.06 & 8 \\
\hline
\end{tabular}

Significance analysis of triplicate microarrays was performed with a false discovery rate of $0.1 \%$ and a minimum probe coverage of 3. ID, Entrez Gene ID; FC: Fold change; Cov: probe coverage; * validated by Taqman realtime RT-PCR

fulfilled these criteria and were analzyed with qRT-PCR. In the first set of experiments, mRNA levels of genes up-regulated by luteolin treatment were assessed (Fig. 3). Transcripts of Sulfirexodin 1 (Srxn1), Biliverdin reductase B (Blvrb), Heme oxigenase 1 (Hmox1), and Glutamate-cysteine ligase (Gclm) are components of the cellular anti-oxidant response [41-43] and were all induced by luteolin treatment (Fig. 3A-D). We could further validate increased levels of Lysophosphatidylcholine acyltransferase (Lpcat1), Ring finger protein 145 (Rnf145), Cd36 antigen, Kinase insert domain receptor (Kdr, alias Vegfr2), and Cd83 antigen. Lpcat1 catalyzes the inactivation of inflammatory lipids [44], whereas $\mathrm{Cd} 36$ and $\mathrm{Kdr}$ are surface receptors required for phagocytic uptake and chemotactic migration, respectively $[45,46]$. The function of Rnf145 is currently unknown.

In the next set of qRT-PCR experiments, down-regulated transcripts involved in pro-inflammatory activation and acute phase response were analyzed. Complement factor C3 (C3), Complement factor b (Cfb), Secreted leukocyte peptidase inhibitor (Slpi), and the pro-inflammatory Guanylate binding proteins 2 (Gbp2) and Gbp3 [47] showed diminished mRNA levels in luteolin-treated samples (Fig. 4A-D). The same tendency was seen in the newly identified microRNA miR-147, which is involved in toll-like receptor signaling [48], the acute phase gene Haptoglobin ( $\mathrm{Hp})$, the stress-related gene Nuclear protein 1 (Nupr1, alias p8) [49], and Cystatin 7 (Cst7) (Fig. 4F-I).
As third group of genes validated by qRT-PCR, four luteolin-repressed genes related to apoptosis and microglial shape formation were studied (Fig. 5A-D). The apoptotic mediators DNA-damage inducible transcript 3 (Ddit3, alias Chop, Gadd153) and Tribbles homolog 3 $[50,51]$ were down-regulated by luteolin in non-activated as well as LPS-activated microglia (Fig. 5A, B), indicating anti-apoptotic protection mechanisms elicited by luteolin. In line with these findings, we also observed reduced expression of the Macrophage receptor with collagenous structure (Marco) and Lipocalin 2 (Lcn2), two molecules with dual roles in apoptosis and de-ramification of activated microglia [52,53].

\section{Luteolin changes microglial morphology and inhibits NO} secretion

To assess whether the particular gene expression profiles measured in luteolin-stimulated microglia translate into detectable functional properties, phenotypic characterization was performed. The general activation state and morphological phenotype of microglia is particularly reflected by their cell shape and cytoskeletal organization. To detected morphological changes and for visualization of filopodia we performed phalloidin staining. Conventional BV-2 microglia cultures were low level activated cells with a flat shape and some filopodia (Fig. $6 \mathrm{~A})$. Culture of BV-2 cells in the presence of luteolin lead to considerable ramification and formation of long protrusions (Fig. 6B), indicating induction of a surveillance state. LPS-activation of BV-2 cells caused 
Table 3 Differentially expressed transcripts after $24 \mathrm{~h}$ stimulation with $50 \mu \mathrm{M}$ luteolin $+50 \mathrm{ng} / \mathrm{ml}$ LPS versus $50 \mathrm{ng} / \mathrm{ml}$ LPS

\begin{tabular}{|c|c|c|c|c|c|}
\hline $\mathrm{Nr}$ & ID & Symbol & Gene Name & $\mathrm{FC}^{*}$ & Cov \\
\hline \multicolumn{6}{|c|}{ UP-REGULATED } \\
\hline 1 & 74315 & Rnf145 & Ring finger protein 145 & 3.27 & 11 \\
\hline 2 & 210992 & Lpcat1 & Lysophosphatidylcholine acyltransferase 1 & 2.55 & 11 \\
\hline 3 & 12522 & $\mathrm{Cd} 83$ & CD83 antigen & 2.51 & 11 \\
\hline 4 & 14630 & Gclm & Glutamate-cysteine ligase, modifier subunit & 2.46 & 10 \\
\hline 5 & 16889 & Lipa & Lysosomal acid lipase A & 2.31 & 6 \\
\hline 6 & 56336 & B4galt5 & UDP-Gal:betaGIcNAc beta 1,4-galactosyltransferase, polypeptide 5 & 2.30 & 8 \\
\hline 7 & 14950 & $\mathrm{H} 13$ & Histocompatibility 13 & 2.30 & 7 \\
\hline 8 & 14104 & Fasn & Fatty acid synthase & 2.28 & 4 \\
\hline 9 & 12125 & $\mathrm{BC}|2| 11$ & BCL2-like 11 & 2.16 & 14 \\
\hline 10 & 16542 & Kdr & Kinase insert domain protein receptor & 2.16 & 9 \\
\hline 11 & 216345 & Ccdc131 & Coiled-coil domain containing 131 & 2.11 & 7 \\
\hline \multicolumn{6}{|c|}{ DOWN-REGULATED } \\
\hline 1 & 66141 & Ifitm3 & Interferon induced transmembrane protein 3 & -13.74 & 9 \\
\hline 2 & 433470 & AA467197 & Expressed sequence AA467197, miR-147 & -9.32 & 9 \\
\hline 3 & 16819 & Len2 & Lipocalin 2 & -6.87 & 10 \\
\hline 4 & 14469 & Gbp2 & Guanylate binding protein 2 & -6.41 & 16 \\
\hline 5 & 14962 & $\mathrm{Cfb}$ & Complement factor B & -5.94 & 8 \\
\hline 6 & 13198 & Ddit3 & DNA-damage inducible transcript 3 & -5.58 & 11 \\
\hline 7 & 16181 & $\| 1 \mathrm{rn}$ & Interleukin 1 receptor antagonist & -5.28 & 33 \\
\hline 8 & 55932 & Gbp3 & Guanylate binding protein 3 & -4.72 & 10 \\
\hline 9 & 56312 & Nupr1 & Nuclear protein 1 & -4.35 & 15 \\
\hline 10 & 75345 & Slamf7 & SLAM family member 7 & -4.14 & 9 \\
\hline 11 & 20210 & Saa3 & Serum amyloid A 3 & -3.78 & 7 \\
\hline 12 & 17386 & Mmp13 & Matrix metallopeptidase 13 & -3.63 & 11 \\
\hline 13 & 15439 & $\mathrm{Hp}$ & Haptoglobin & -3.56 & 11 \\
\hline 14 & 17167 & Marco & Macrophage receptor with collagenous structure & -3.34 & 8 \\
\hline 15 & 12266 & $\mathrm{C} 3$ & Complement component 3 & -3.29 & 6 \\
\hline 16 & 12870 & $\mathrm{Cp}$ & Ceruloplasmin & -3.05 & 5 \\
\hline 17 & 13011 & Cst7 & Cystatin F & -3.03 & 9 \\
\hline 18 & 23882 & Gadd45g & Growth arrest and DNA-damage-inducible 45 gamma & -2.95 & 11 \\
\hline 19 & 242341 & Atp6rod2 & ATPase, $\mathrm{H}+$ transporting, lysosomal V0 subunit D2 & -2.81 & 13 \\
\hline 20 & 68774 & Ms4a6d & Membrane-spanning 4-domains, subfamily A, member 6D & -2.75 & 19 \\
\hline 21 & 83673 & Snhg1 & Small nucleolar RNA host gene 1 & -2.75 & 24 \\
\hline 22 & 12494 & $\mathrm{Cd} 38$ & CD38 antigen & -2.73 & 6 \\
\hline 23 & 19655 & Rbmx & RNA binding motif protein, $X$ chromosome & -2.73 & 11 \\
\hline 24 & 56405 & Dusp14 & Dual specificity phosphatase 14 & -2.68 & 10 \\
\hline 25 & 213002 & Ifitm6 & Interferon induced transmembrane protein 6 & -2.57 & 8 \\
\hline 26 & 12517 & $\mathrm{Cd} 72$ & CD72 antigen & -2.55 & 9 \\
\hline 27 & 14129 & Fcgr1 & Fc receptor, IgG, high affinity I & -2.55 & 11 \\
\hline 28 & 14130 & Fcgr2b & Fc receptor, lgG, low affinity IIb & -2.48 & 27 \\
\hline 29 & 231532 & Arhgap24 & Rho GTPase activating protein 24 & -2.46 & 8 \\
\hline 30 & 29818 & Hspb7 & Heat shock protein family, member 7 (cardiovascular) & -2.45 & 5 \\
\hline 31 & 17476 & Mpeg1 & Macrophage expressed gene 1 & -2.43 & 6 \\
\hline 32 & 66222 & Serpinb1a & Serine peptidase inhibitor, clade $B$, member 1a & -2.41 & 10 \\
\hline 33 & 78771 & Mctp1 & Multiple C2 domains, transmembrane 1 & -2.39 & 8 \\
\hline 34 & 20568 & Slpi & Secretory leukocyte peptidase inhibitor & -2.39 & 9 \\
\hline 35 & 12507 & Cd5 & CD5 antigen & -2.35 & 9 \\
\hline 36 & 50778 & Rgs1 & Regulator of G-protein signaling 1 & -2.35 & 11 \\
\hline 37 & 21897 & TIr1 & Toll-like receptor 1 & -2.20 & 5 \\
\hline
\end{tabular}




\begin{tabular}{rlllrl}
38 & 16149 & Cd74 & CD74 antigen & -2.17 & 5 \\
39 & 73167 & Arhgap8 & Rho GTPase activating protein 8 & -2.13 & 8 \\
40 & 15064 & Mr1 & Major histocompatibility complex, class I-related & -2.06 & 7 \\
41 & 347722 & Centg2 & Centaurin, gamma 2 & -2.04 & 11 \\
42 & 98365 & Slamf9 & SLAM family member 9 & -2.04 & 8 \\
43 & 72999 & Insig2 & Insulin induced gene 2 & -2.00 & 8 \\
\hline
\end{tabular}

Significance analysis of triplicate microarrays was performed with a false discovery rate of $0.1 \%$ and a minimum probe coverage of 3. ID, Entrez Gene ID; FC: Fold change; Cov: probe coverage; * validated by Taqman realtime RT-PCR
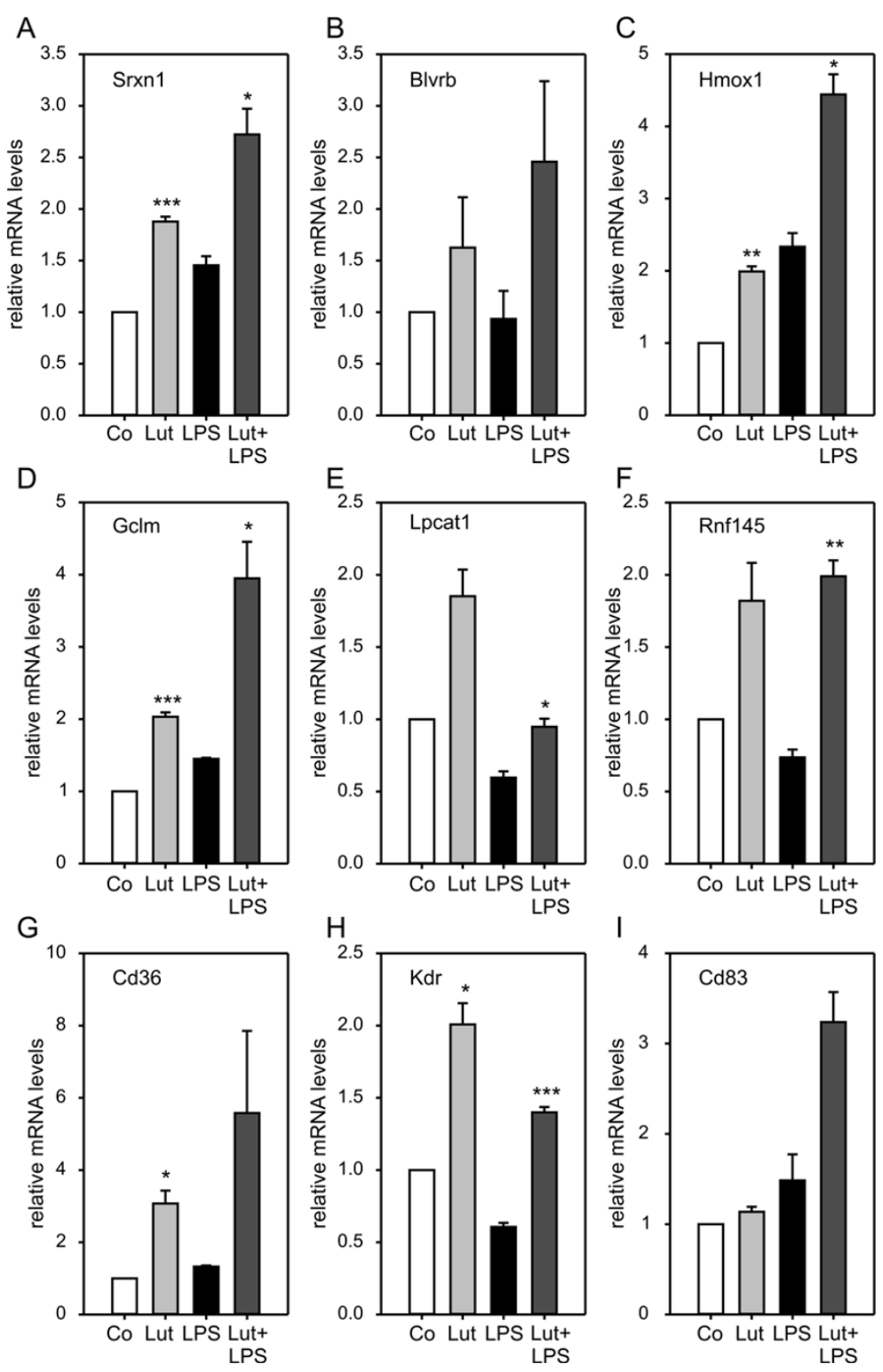

Figure 3 Luteolin induces anti-oxidant, anti-inflammtory, and survival pathways. Real-time qRT-PCR validation of transcripts in BV-2 microglia stimulated with $50 \mu \mathrm{M}$ luteolin, $50 \mathrm{ng} / \mathrm{ml}$ LPS, or $50 \mu \mathrm{M}$ luteolin $+50 \mathrm{ng} / \mathrm{ml}$ LPS. Relative mRNA levels were quantified for (A) Sulfiredoxin 1 (Srxn1), (B) Biliverdin reductase b (Blvrb), (C) Heme oxigenase 1 (Hmox1), (D) Glutamate-cysteine ligase modifier subunit (Gclm), (E) Lysophosphatidylcholine acyltransferase 1 (Lpcat1), (F) Ring finger protein 145 (Rnf145), (G) Cd36 antigen (Cd36), (H) Kinase insert domain protein receptor (Kdr), and (I) Cd83 antigen (Cd83). Expression was normalized to the control gene Gusb and mRNA levels (+/- SEM) are graphed relative to mock-treated control cells. Results are calculated from three independent experiments performed in triplicate measurements. ${ }^{*} p \leq 0.05,{ }^{* *} p$ $\leq 0.01,{ }^{* *} p \leq 0.001$ for luteolin vs. control and luteolin + LPS vs. LPS, respectively. 

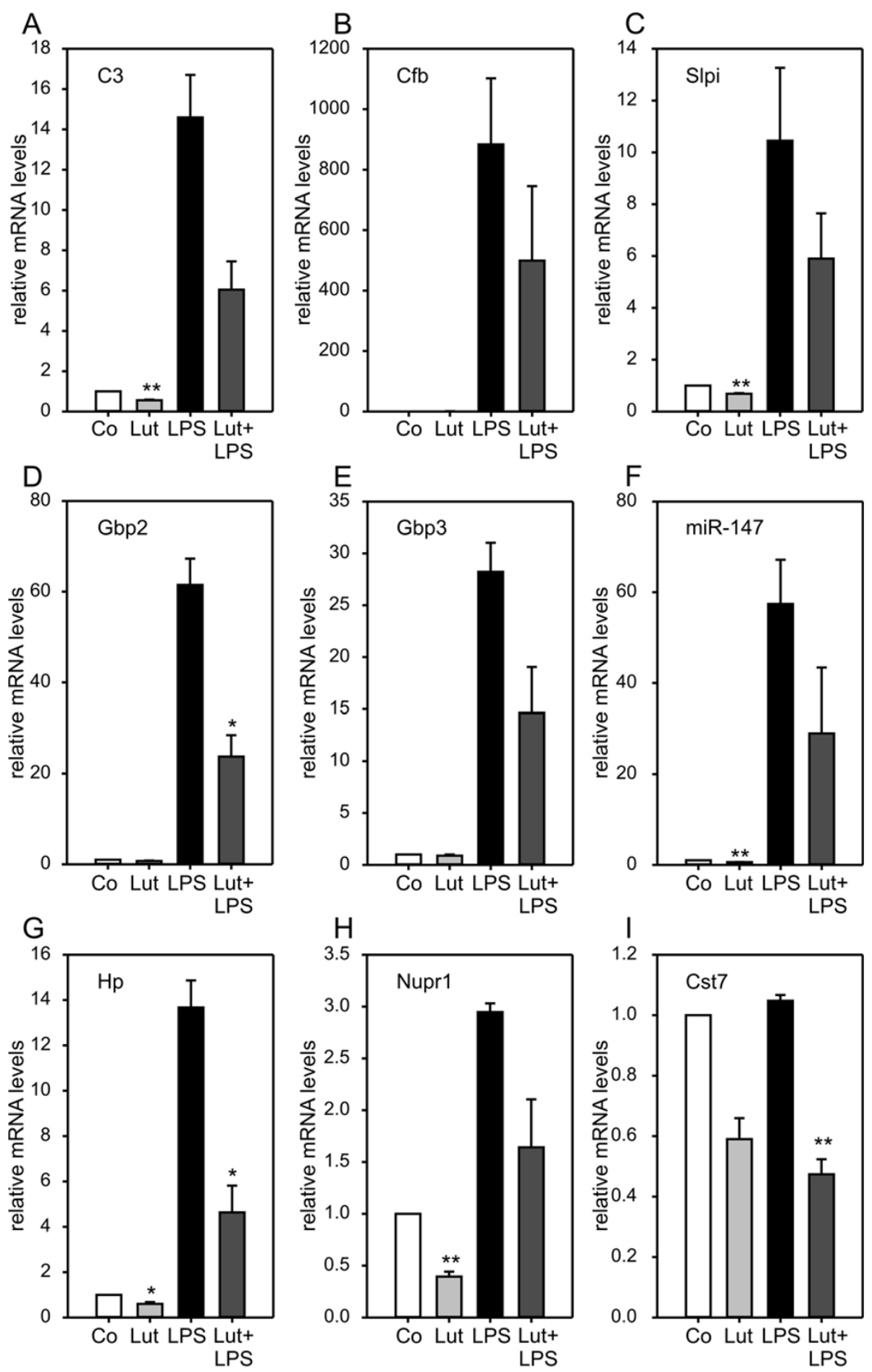

Figure 4 Luteolin inhibits pro-inflammtory and stress-related pathways. Real-time qRT-PCR validation of transcripts in BV-2 microglia stimulated with $50 \mu \mathrm{M}$ luteolin, $50 \mathrm{ng} / \mathrm{ml}$ LPS, or $50 \mu \mathrm{M}$ luteolin $+50 \mathrm{ng} / \mathrm{ml}$ LPS. Relative mRNA levels were quantified for (A) Complement component 3 (C3), (B) Complement factor B (Cfb), (C) Serine leukocyte peptidase inhibitor (Spli), (D) Guanylate binding protein 2 (Gnbp2), (E) Guanylate binding protein 3 (Gnbp3), (F) micro RNA 147 (miR-147), (G) Haptoglobin (Hp), (H) Nuclear protein 1 (Nupr1), and (I) Cystatin F (Cst7). Expression was normalized to the control gene Gusb and mRNA levels (+/- SEM) are graphed relative to mock-treated control cells. Results are calculated from three independent experiments performed in triplicate measurements. ${ }^{*} p \leq 0.05,{ }^{* *} p \leq 0.01$ for luteolin vs. control and luteolin + LPS vs. LPS, respectively. 

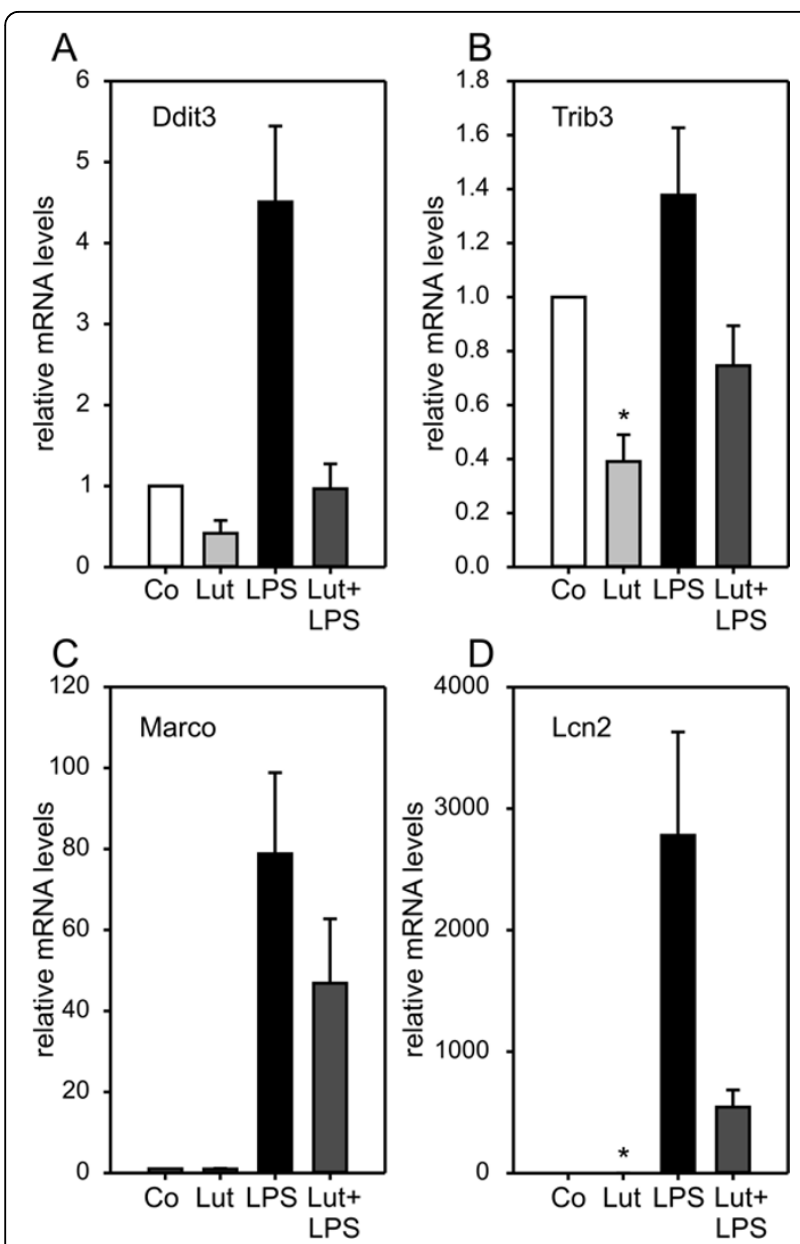

Figure 5 Luteolin inhibits apoptosis-related pathways and reduces de-ramification genes. Real-time qRT-PCR validation of transcripts in BV-2 microglia stimulated with $50 \mu \mathrm{M}$ luteolin, $50 \mathrm{ng} /$ $\mathrm{ml}$ LPS, or $50 \mu \mathrm{M}$ luteolin $+50 \mathrm{ng} / \mathrm{ml}$ LPS. Relative mRNA levels were quantified for (A) DNA-damage inducible transcript 3 (Ddit3), (B) Tribbles homolog 3 (Trib3), (C) Macrophage receptor with collagenous structure (Marco), and (D) lipocalin 2 (Lcn2). Expression was normalized to the control gene Gusb and mRNA levels (+/SEM) are graphed relative to mock-treated control cells. Results are calculated from three independent experiments performed in triplicate measurements. ${ }^{*} p \leq 0.05$ for luteolin vs. control and luteolin + LPS vs. LPS, respectively.

formation of a round cell shape with retracted filopodia (Fig. 6C). In contrast, co-incubation of LPS-treated cells with luteolin sustained the ramified microglial morphology (Fig. 6D). A similar effect was seen in primary mouse microglia, where luteolin increased the length of filopodia in non-activated cells (Fig. 6E, F) and caused flatening and ramification of LPS-treated cells (Fig. 6G, $\mathrm{H})$. To test the direct effect of luteolin on microglial secretion of toxic metabolites, NO levels were determined in the supernatant of BV-2 cells. Treatment of BV-2 cells with luteolin alone did not result in increased NO concentrations (Fig. 6I), whereas stimulation with
LPS markedly increased secreted NO levels. Co-incubation of LPS-activated cells with luteolin nearly completely abolished NO secretion (Fig. 6I). These data indicate that luteolin favors the ramified surveillance state of microglia and effectively inhibits cytotoxic NO formation. Kim et al. previously reported that luteolin triggered a blockade of NO secretion in LPS-stimulated BV-2 microglia, which was mediated by inhibition of inducible NO synthase (iNos) protein expression [54]. To indenpendently verify these data by qRT-PCR, we analyzed iNos mRNA levels in BV-2 cells treated with luteolin, LPS, or both simultaneously. LPS caused a more than 40 -fold increase in iNos transcripts and luteolin co-treatment significantly reduced iNos levels more than 2-fold. Thus, our expression data corroborate the findings by Kim et al. and provide a reasonable explanation for reduced NO secretion levels.

To test the hypothesis that luteolin leads to decreased microglial neurotoxicity, a culture system of $661 \mathrm{~W}$ photoreceptor cells with conditioned medium (CM) from BV-2 cells or primary microglia was established. $661 \mathrm{~W}$, a retina-derived cell line [55], represents a valuable model to study microglial neurotoxicity in the special context of retinal degeneration [36]. $661 \mathrm{~W}$ cells were incubated for $24 \mathrm{~h}$ with culture supernatants from unstimulated, luteolin-, LPS- or LPS + luteolin-treated cells and $661 \mathrm{~W}$ photoreceptor cell morphology was assessed by phase contrast microscopy. $661 \mathrm{~W}$ cells in their own medium grew confluent after $24 \mathrm{~h}$ and the presence of CM from control- or luteolin-treated BV-2 cells did not affect cell morphology (Fig. 7A, B). As described previously [56], confluent $661 \mathrm{~W}$ cells flattened out and often multiple cells were connected to each other through their projected extensions (Fig. 7A, B). In contrast, $661 \mathrm{~W}$ cells co-incubated with LPS-stimulated BV-2 supernatant appeared elongated and smaller, leading to prominent cell-free areas present in the culture (Fig. 7C). When adding CM from LPS + luteolin-stimulated BV-2 cells, nearly normal cell characteristics were retained (Fig. 7D). Similar morphological changes of $661 \mathrm{~W}$ cells were observed when cultured in the presence of primary microglia CM (Fig. 7E-H). Direct incubation of photoreceptor cells with LPS, luteolin, or both had no effects on cell morphology (data not shown), indicating that the observed changes in $661 \mathrm{~W}$ cell growth arise from secreted microglial compounds.

To correlate the microscopic findings with functional data, we next studied the influence of microglia-secreted products on caspase-related apoptotic signaling in the neuronal cell model. $661 \mathrm{~W}$ cells cultured in the presence of CM from LPS-stimulated BV-2 cells displayed a strong induction of caspase 3/7 activity (Fig. 7I). When CM from microglia co-treated with LPS + luteolin was used, $661 \mathrm{~W}$ apoptosis was still present but was 

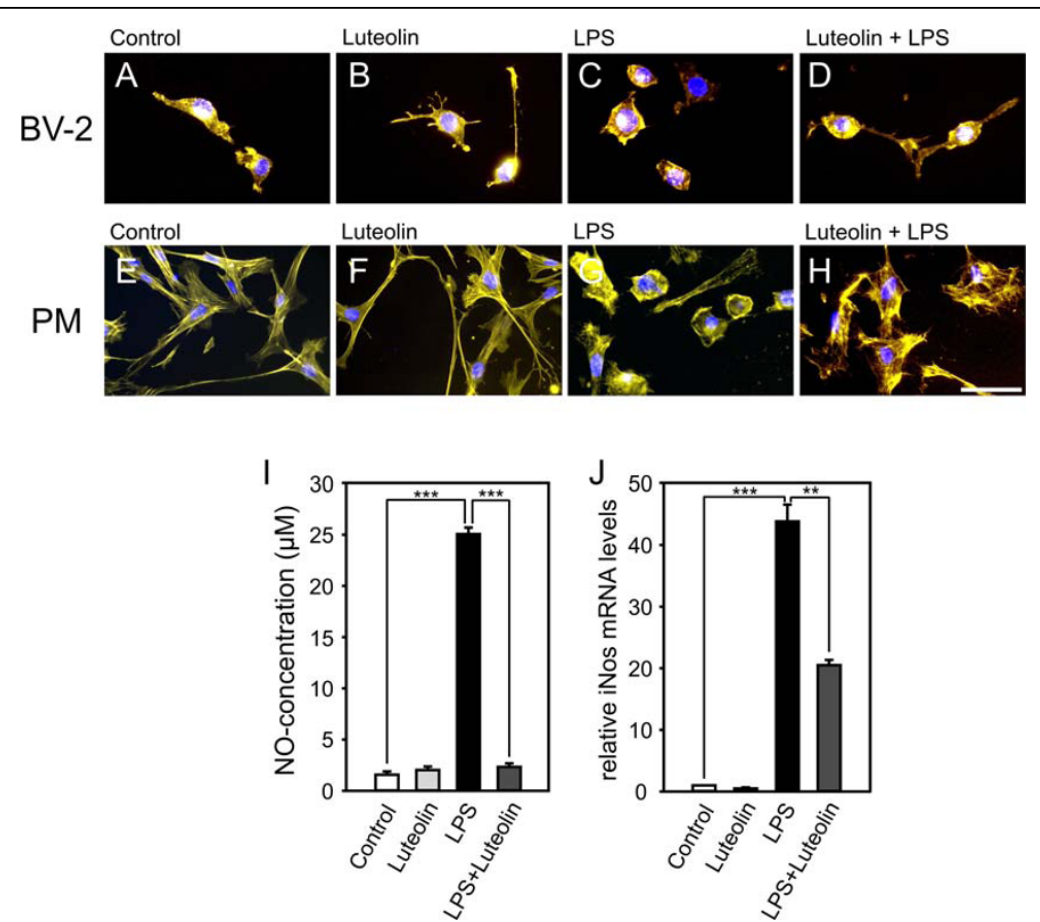

Figure 6 Luteolin promotes ramification of microglia and inhibits NO-synthesis. Effects of luteolin, LPS and Luteolin + LPS on BV-2 (A-D) and primary brain microglia (E-H) cell morphology and actin cytoskeleton. Phallodin-TRITC-staining of F-actin bundles and DAPI costaining reveals that $24 \mathrm{~h}$ treatment with $50 \mathrm{\mu M}$ luteolin in non-activated (B, F) or LPS-activated microglia (D, H) supports ramification. (I) NO release from BV-2 cells treated for $24 \mathrm{~h}$ with $50 \mu \mathrm{M}$ luteolin, $50 \mathrm{ng} / \mathrm{ml}$ LPS, or LPS + luteolin. The micrographs and data shown are from one representative experiment out of three independent experiments with the same tendencies. Scale bar, $50 \mu \mathrm{M}$. (J) Real-time qRT-PCR analysis of iNos transcripts in BV-2 microglia stimulated with $50 \mu \mathrm{M}$ luteolin, $50 \mathrm{ng} / \mathrm{ml}$ LPS, or $50 \mu \mathrm{M}$ luteolin $+50 \mathrm{ng} / \mathrm{ml}$ LPS. Expression was normalized to the control gene Gusb and mRNA levels (+/- SEM) are graphed relative to mock-treated control cells. Results are calculated from two independent experiments performed in triplicate measurements. ${ }^{* *} p \leq 0.001{ }^{* *} p \leq 0.01$ for LPS vs. control and luteolin + LPS vs. LPS, respectively.

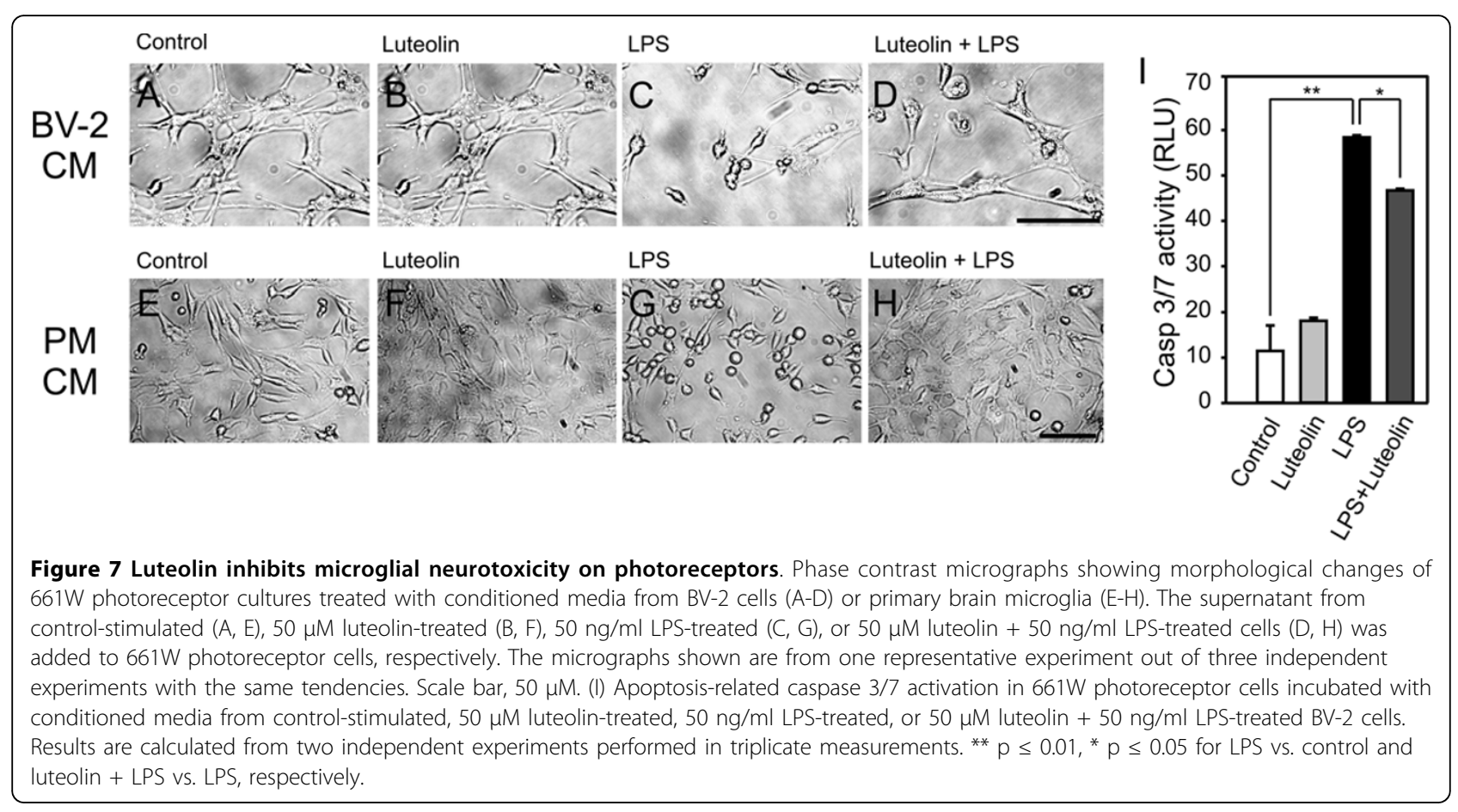


significantly diminished (Fig. 7I). Culture media from BV-2 cells kept in the presence of luteolin alone had no effect on $661 \mathrm{~W}$ apoptosis. These findings implicate that luteolin either stimulates microglia to produce less proapoptotic substances or actively promotes the release of survival signals.

\section{Discussion}

Like other plant-derived flavonoids, luteolin has a variety of biological activities including well-known anti-mutagenic and anti-tumorigenic properties [57]. Moreover, this flavone possesses direct anti-oxidant activity, which is attributed to structural features of all flavonoids, which favor scavenging of reactive oxygen and nitrogen species [58]. Although the anti-oxidant and anti-inflammatory activities of luteolin may be also useful in the treatment of many chronic inflammatory diseases including neurodegeneration, only little information is available about luteolin-mediated transcriptional mechanisms or molecular targets in microglia [59].

We have therefore performed the first genome-wide study of luteolin-mediated transcriptional effects in microglia. To our surprise, luteolin treatment did not only change expression levels of a few transcripts but had a broad and strong impact on the transcriptome of resting and particularly of LPS-activated microglia. The microarray dataset and the qRT-PCR validations revealed several luteolin-regulated pathways. Luteolin caused simultaneous up-regulation of four important anti-oxidant enzymes Srxn1, Blvrb, Gclm, and Hmox1. These data are consistent with earlier findings demonstrating increased Hmox1 transcription in RAW264.7 macrophages after luteolin treatment [60]. Stimulation with the flavonoid induced binding of the transcription factor NFE2-related factor 2 (Nrf2) to anti-oxidant response elements (ARE) in the Hmox1 promoter region [60]. Luteolin is a potent activator of Nrf2 [61] and the majority of anti-oxidant enzymes contain ARE in their regulatory regions, including Srxn1 [62]. Moreover, mouse embryonic fibroblasts derived from Nrf2 -/- mice showed significantly lower Blvrb and Gclm mRNA levels upon Diquat induction [63]. Therefore, we speculate that increased microglial expression of Srxn1, Blvrb, and Gclm is also mediated by activation of Nrf2. This hypothesis is further corroborated by the protective functions of Nrf2 in several microglia-related neurodegenerative disorders [64].

Luteolin significantly enhanced mRNA synthesis of five other genes involved in different biological pathways. Lpcat1 is a lysophospholipid acyltransferase implicated in anti-inflammatory responses by converting lysoplatelet activation factor (lyso-PAF) to PAF and lysophosphatidylcholine (lyso-PC) to PC [65]. LPC exerts considerable neuro-inflammatory reactivity in the brain and inhibition of LPC signaling in astrocytes and microglia confers neuroprotection [66]. Lpcat1 is also highly expressed in the retina [44], indicating that luteolin-induced Lpact1 levels could lead to diminished LPC levels in retinal microglia. Rnf145 was also up-regulated by luteolin but the function of this protein remains to be determined. Cd36 and Kdr (alias Vegfr2) were also significantly induced by luteolin in non-activated as well as activated microglia. The pattern recognition receptor Cd36 signals to the actin cytoskeleton and regulates microglial migration and phagocytosis [67], whereas $\mathrm{Kdr}$ is involved in the chemotactic response of microglia [46]. We thus speculate that luteolin-mediated expression of both genes could result in increased phagocytic responses of microglia without inducing inflammation.

Several reports have demonstrated that luteolin inhibits pro-inflammatory cytokine expression in various cell types by blocking NFkB (reviewed in [28]). Our microarray data confirmed these findings and revealed further NFkB target genes including the recently discovered microRNA miR-147 [48]. Recently, Jang et al. showed that luteolin reduced Il6 production mainly by inhibiting JNK signaling and AP1 activation [34]. Luteolin did not affect IkB- $\alpha$ degradation or NFkB DNA binding in brain microglia, implicating that luteolinmediated effects in microglia are not solely dependent on NFkB blockade [34]. In line with this notion, our luteolin-regulated expression profiles identified several genes with NFkB-independent promoter control. Likewise, luteolin down-regulated complement factor 3, which is regulated by AP1 [68] and blocked expression of Slpi, which is a target of interferon regulatory factor 1 (IRF1) [69]. Luteolin also diminished mRNA levels of the pro-inflammatory GTPase Gbp2 and the acute phase protein Haptoglobin, which are both regulated by signal transducers and activators of transcription (STATs) $[70,71]$. These data clearly show that luteolin dampens microglia activation by interfering with several divergent signaling pathways.

The luteolin-regulated differential expression patterns also revealed genes involved in microglial apoptosis and ramification. Microglia are more susceptible than macrophages to apoptosis [72] and recent evidence indicates that microglial apoptosis and senescence may precede neurodegeneration [73]. Ddit 3 and Trib3, which were both induced by LPS and suppressed by luteolin, support stress and NO-mediated apoptosis [50,51]. We therefore hypothesize that luteolin could promote the survival of activated and stressed microglia in an environment of early neurodegeneration. Our expression data also revealed the unexpected finding that luteolin downregulated Lcn2 and Marco, two molecules involved in microglial ramification and formation of filopodia. Lee et al. demonstrated that stable expression of Lcn in BV2 microglia, the same cell line we used in our 
experiments, induced a round cell shape with a loss of processes [52]. In line with this, over-expression of the scavenger receptor Marco in dendritic cells caused rounding of cells and down-regulated antigen uptake [53]. Thus, we hypothesized that the observed changes in mRNA levels of both genes might also translate into different morphological characters.

The morphological and functional assays fully supported the implications from gene expression profiles and revealed a direct effect of luteolin on the microglial phenotype. Luteolin stimulated the formation of filopodia and caused ramification of BV-2 cells and primary microglia even in the setting of strong LPS activation. Moreover, NO secretion was completely blocked in LPS-activated microglia upon co-incubation with luteolin. We studied the effects of conditioned media from microglia on cultured photoreceptor-like $661 \mathrm{~W}$ cells and demonstrated that luteolin-treatment effectively protected $661 \mathrm{~W}$ cells from LPS-induced microglial toxicity. Since NO and other reactive oxygen species are the major radicals secreted from microglia, we speculate that luteolin directly inhibits the secretion of these cytotoxic radicals. Our hypothesis is corroborated by recent data demonstrating that luteolin concentration-dependently attenuated LPS-induced dopaminergic neuron loss by blocking NO secretion from cultured rat microglia [32].

\section{Conclusions}

We have shown that the flavonoid luteolin is a potent modulator of microglial activation, cell shape, and effector functions. Luteolin induced global changes in the transcriptome of resting or LPS-activated microglia leading to a polarized M2-like phenotype with anti-inflammatory and neuroprotective characteristics. Luteolin's mechanisms of action appear to target several independent pathways independent of NFkB. Our results provide a basis to develop immuno-modulatory and neuroprotective therapies for the treatment of neurodegenerative disoders.

\footnotetext{
Acknowledgements

This work was supported by grants from the German Research Foundation (FOR1075 Project 4), the Elite Network of Bavaria, and the Pro Retina Foundation. The authors thank Prof. Muayyad Al Ubaidi for providing the $661 \mathrm{~W}$ photoreceptor cell line.

\section{Author details}

Institute of Human Genetics, University of Regensburg, Franz-Josef-StraussAllee 11, 93053 Regensburg, Germany. ${ }^{2}$ Center of Excellence for Fluorescent Bioanalytics, University of Regensburg, Josef-Engert-Str 9, 93053 Regensburg, Germany. ${ }^{3}$ Institute of Human Anatomy and Embryology, University of Regensburg, Universitätsstr 31, 93053 Regensburg, Germany.
}

\section{Authors' contributions}

$K D, S E$, and DK carried out all cell cultures and GRT-PCR experiments. MK, JH, and YW analyzed qRT-PCR and functional data. CM performed microarray hybridizations and raw data analyses. RF analyzed microarray data and critically read the manuscript. TL designed the study, obtained funding, carried out biostatistical analyses of microarrays and wrote the manuscript. All authors read and approved the final manuscript.

\section{Competing interests}

The authors declare that they have no competing interests.

Received: 2 December 2009

Accepted: 14 January 2010 Published: 14 January 2010

\section{References}

1. Hanisch UK: Microglia as a source and target of cytokines. Glia 2002, 40:140-155.

2. Hanisch UK, Kettenmann $\mathrm{H}$ : Microglia: active sensor and versatile effector cells in the normal and pathologic brain. Nat Neurosci 2007, 10:1387-1394.

3. Streit WJ: Microglia as neuroprotective, immunocompetent cells of the CNS. Glia 2002, 40:133-139.

4. Streit WJ: Microglia and neuroprotection: implications for Alzheimer's disease. Brain Res Brain Res Rev 2005, 48:234-239.

5. Giulian D, Li J, Bartel S, Broker J, Li X, Kirkpatrick JB: Cell surface morphology identifies microglia as a distinct class of mononuclear phagocyte. J Neurosci 1995, 15:7712-7726.

6. Davalos D, Grutzendler J, Yang G, Kim JV, Zuo Y, Jung S, Littman DR, Dustin ML, Gan WB: ATP mediates rapid microglial response to local brain injury in vivo. Nat Neurosci 2005, 8:752-758.

7. Nimmerjahn A, Kirchhoff F, Helmchen F: Resting microglial cells are highly dynamic surveillants of brain parenchyma in vivo. Science 2005, 308:13141318.

8. Broderick C, Hoek RM, Forrester JV, Liversidge J, Sedgwick JD, Dick AD: Constitutive retinal CD200 expression regulates resident microglia and activation state of inflammatory cells during experimental autoimmune uveoretinitis. Am J Pathol 2002, 161:1669-1677.

9. Cardona AE, Pioro EP, Sasse ME, Kostenko V, Cardona SM, Dijkstra IM, Huang D, Kidd G, Dombrowski S, Dutta R, Lee JC, Cook DN, Jung S, Lira SA, Littman DR, Ransohoff RM: Control of microglial neurotoxicity by the fractalkine receptor. Nat Neurosci 2006, 9:917-924.

10. Dick AD, Carter D, Robertson M, Broderick C, Hughes E, Forrester JV, Liversidge J: Control of myeloid activity during retinal inflammation. J Leukoc Biol 2003, 74:161-166.

11. Haynes SE, Hollopeter G, Yang G, Kurpius D, Dailey ME, Gan WB, Julius D: Control of myeloid activity during retinal inflammation. Nat Neurosci 2006, 9:1512-1519.

12. Ransohoff RM, Perry VH: Microglial physiology: unique stimuli, specialized responses. Annu Rev Immunol 2009, 27:119-145.

13. El Khoury J, Luster AD: Mechanisms of microglia accumulation in Alzheimer's disease: therapeutic implications. Trends Pharmacol Sci 2008 29:626-632.

14. Orr CF, Rowe DB, Halliday GM: An inflammatory review of Parkinson's disease. Prog Neurobiol 2002, 68:325-340.

15. Sargsyan SA, Monk PN, Shaw PJ: Microglia as potential contributors to motor neuron injury in amyotrophic lateral sclerosis. Glia 2005, 51:241253.

16. Raivich G, Banati R: Brain microglia and blood-derived macrophages: molecular profiles and functional roles in multiple sclerosis and animal models of autoimmune demyelinating disease. Brain Res Brain Res Rev 2004, 46:261-281.

17. Langmann T: Microglia activation in retinal degeneration. J Leukoc Biol 2007, 81:1345-1351.

18. Schuetz E, Thanos S: Microglia-targeted pharmacotherapy in retinal neurodegenerative diseases. Curr Drug Targets 2004, 5:619-627.

19. Hume DA: Differentiation and heterogeneity in the mononuclear phagocyte system. Mucosal Immunol 2008, 1:432-441.

20. Gordon S, Taylor PR: Monocyte and macrophage heterogeneity. Nat Rev Immunol 2005, 5:953-964.

21. Mosser DM: Monocyte and macrophage heterogeneity. J Leukoc Biol 2003, 73:209-212.

22. Martinez FO, Sica A, Mantovani A, Locati M: Macrophage activation and polarization. Front Biosci 2008, 13:453-461.

23. Michelucci A, Heurtaux T, Grandbarbe L, Morga E, Heuschling P: Characterization of the microglial phenotype under specific pro- 
inflammatory and anti-inflammatory conditions: Effects of oligomeric and fibrillar amyloid-beta. J Neuroimmunol 2009, 210:3-12.

24. Jimenez S, Baglietto-Vargas D, Caballero C, Moreno-Gonzalez I, Torres M, Sanchez-Varo R, Ruano D, Vizuete M, Gutierrez A, Vitorica J: Inflammatory response in the hippocampus of PS1M146L/APP751SL mouse model of Alzheimer's disease: age-dependent switch in the microglial phenotype from alternative to classic. J Neurosci 2008, 28:11650-11661.

25. Kigerl KA, Gensel JC, Ankeny DP, Alexander JK, Donnelly DJ, Popovich PG: Identification of two distinct macrophage subsets with divergent effects causing either neurotoxicity or regeneration in the injured mouse spinal cord. J Neurosci 2009, 29:13435-13444.

26. Zhang Z, Zhang ZY, Schluesener HJ: Compound A, a plant origin ligand of glucocorticoid receptors, increases regulatory $\mathrm{T}$ cells and $\mathrm{M} 2$ macrophages to attenuate experimental autoimmune neuritis with reduced side effects. J Immunol 2009, 183:3081-3091.

27. Lleo A, Galea E, Sastre M: Molecular targets of non-steroidal antiinflammatory drugs in neurodegenerative diseases. Cell Mol Life Sci 2007, 64:1403-1418

28. Lopez-Lazaro M: Distribution and biological activities of the flavonoid luteolin. Mini Rev Med Chem 2009, 9:31-59.

29. Chen CY, Peng WH, Tsai KD, Hsu SL: Luteolin suppresses inflammationassociated gene expression by blocking NF-kappaB and AP-1 activation pathway in mouse alveolar macrophages. Life Sci 2007, 81:1602-1614.

30. Hu C, Kitts DD: Luteolin and luteolin-7-O-glucoside from dandelion flower suppress iNOS and COX-2 in RAW264.7 cells. Mol Cell Biochem 2004, 265:107-113.

31. Harris GK, Qian Y, Leonard SS, Sbarra DC, Shi X: Luteolin and chrysin differentially inhibit cyclooxygenase-2 expression and scavenge reactive oxygen species but similarly inhibit prostaglandin-E2 formation in RAW 264.7 cells. J Nutr 2006, 136:1517-1521.

32. Chen $H Q$, Jin $Z Y$, Wang $X J$, Xu XM, Deng L, Zhao JW: Luteolin protects dopaminergic neurons from inflammation-induced injury through inhibition of microglial activation. Neurosci Lett 2008, 448:175-179.

33. Rezai-Zadeh K, Ehrhart J, Bai Y, Sanberg PR, Bickford P, Tan J, Shytle RD: Apigenin and luteolin modulate microglial activation via inhibition of STAT1-induced CD40 expression. J Neuroinflammation 2008, 5:41.

34. Jang S, Kelley KW, Johnson RW: Luteolin reduces IL-6 production in microglia by inhibiting JNK phosphorylation and activation of AP-1. Proc Natl Acad Sci USA 2008, 105:7534-7539.

35. Shimoi K, Okada H, Furugori M, Goda T, Takase S, Suzuki M, Hara Y, Yamamoto H, Kinae N: Intestinal absorption of luteolin and luteolin 7-Obeta-glucoside in rats and humans. FEBS Lett 1998, 438:220-224.

36. Ebert S, Schoeberl T, Walczak Y, Stoecker K, Stempfl T, Moehle C, Weber BH, Langmann T: Chondroitin sulfate disaccharide stimulates microglia to adopt a novel regulatory phenotype. J Leukoc Biol 2008, 84:736-740.

37. Brazma A, Hingamp P, Quackenbush J, Sherlock G, Spellman P, Stoeckert C, Aach J, Ansorge W, Ball CA, Causton HC, Gaasterland T, Glenisson P, Holstege FC, Kim IF, Markowitz V, Matese JC, Parkinson H, Robinson A Sarkans U, Schulze-Kremer S, Stewart J, Taylor R, Vilo J, Vingron M: Minimum information about a microarray experiment (MIAME)-toward standards for microarray data. Nat Genet 2001, 29:365-371

38. Eichler GS, Huang S, Ingber DE: Gene Expression Dynamics Inspector (GEDI): for integrative analysis of expression profiles. Bioinformatics 2003, 19:2321-2322

39. Dennis G Jr, Sherman BT, Hosack DA, Yang J, Gao W, Lane HC, Lempicki RA: DAVID: Database for Annotation, Visualization, and Integrated Discovery. Genome Biol 2003, 4:3.

40. Weigelt $K$, Lichtinger M, Rehli M, Langmann T: Transcriptomic profiling identifies a PU.1 regulatory network in macrophages. Biochem Biophys Res Commun 2009, 380:308-312.

41. Wegiel B, Baty CJ, Gallo D, Csizmadia E, Scott JR, Akhavan A, Chin BY, Kaczmarek E, Alam J, Bach FH, Zuckerbraun BS, Otterbein LE: Cell surface biliverdin reductase mediates biliverdin-induced anti-inflammatory effects via phosphatidylinositol 3-kinase and Akt. J Biol Chem 2009, 284:21369-21378.

42. Doi Y, Mizuno T, Maki Y, Jin S, Mizoguchi H, Ikeyama M, Doi M, Michikawa M, Takeuchi H, Suzumura A: Microglia activated with the tolllike receptor 9 ligand $\mathrm{CpG}$ attenuate oligomeric amyloid \{beta\} neurotoxicity in in vitro and in vivo models of Alzheimer's disease. Am J Pathol 2009, 175:2121-2132.
43. Bea F, Hudson FN, Chait A, Kavanagh TJ, Rosenfeld ME: Induction of glutathione synthesis in macrophages by oxidized low-density lipoproteins is mediated by consensus antioxidant response elements. Circ Res 2003, 92:386-393.

44. Cheng L, Han X, Shi Y: A Regulatory Role of LPCAT1 in the Synthesis of Inflammatory Lipids, PAF and LPC, in the Retina of Diabetic Mice. Am $J$ Physiol Endocrinol Metab 2009.

45. Koenigsknecht J, Landreth G: Microglial phagocytosis of fibrillar betaamyloid through a beta1 integrin-dependent mechanism. J Neurosci 2004, 24:9838-9846.

46. Ryu JK, Cho T, Choi HB, Wang YT, McLarnon JG: Microglial VEGF receptor response is an integral chemotactic component in Alzheimer's disease pathology. J Neurosci 2009, 29:3-13.

47. Shenoy AR, Kim BH, Choi HP, Matsuzawa T, Tiwari S, MacMicking JD: Emerging themes in IFN-gamma-induced macrophage immunity by the p47 and p65 GTPase families. Immunobiology 2007, 212:771-784.

48. Liu G, Friggeri A, Yang Y, Park YJ, Tsuruta Y, Abraham E: miR-147, a microRNA that is induced upon Toll-like receptor stimulation, regulates murine macrophage inflammatory responses. Proc Natl Acad Sci USA 2009, 106:15819-15824.

49. Plant SR, Wang Y, Vasseur S, Thrash JC, McMahon EJ, Bergstralh DT, Arnett HA, Miller SD, Carson MJ, lovanna JL, Ting JP: Upregulation of the stress-associated gene $\mathrm{p} 8$ in mouse models of demyelination and in multiple sclerosis tissues. Glia 2006, 53:529-537.

50. Gotoh T, Oyadomari S, Mori K, Mori M: Nitric oxide-induced apoptosis in RAW 264.7 macrophages is mediated by endoplasmic reticulum stress pathway involving ATF6 and CHOP. J Biol Chem 2002, 277:12343-12350.

51. Shang $Y Y$, Wang $Z H$, Zhang $L P$, Zhong $M$, Zhang $Y$, Deng JT, Zhang $W$ : TRB3, upregulated by ox-LDL, mediates human monocyte-derived macrophage apoptosis. Febs $J$ 2009, 276:2752-2761.

52. Lee S, Lee J, Kim S, Park JY, Lee WH, Mori K, Kim SH, Kim IK, Suk K: A dual role of lipocalin 2 in the apoptosis and deramification of activated microglia. J Immunol 2007, 179:3231-3241

53. Granucci F, Petralia F, Urbano M, Citterio S, Di Tota F, Santambrogio L, Ricciardi-Castagnoli P: The scavenger receptor MARCO mediates cytoskeleton rearrangements in dendritic cells and microglia. Blood 2003, 102:2940-2947.

54. Kim JS, Lee HJ, Lee MH, Kim J, Jin C, Ryu JH: Luteolin inhibits LPSstimulated inducible nitric oxide synthase expression in BV-2 microglial cells. Planta Med 2006, 72:65-68.

55. Al-Ubaidi MR, Font RL, Quiambao AB, Keener MJ, Liou Gl, Overbeek PA, Baehr W: Bilateral retinal and brain tumors in transgenic mice expressing simian virus 40 large $T$ antigen under control of the human interphotoreceptor retinoid-binding protein promoter. J Cell Biol 1992, 119:1681-1687.

56. Tan E, Ding XQ, Saadi A, Agarwal N, Naash Ml, Al-Ubaidi MR: Expression of cone-photoreceptor-specific antigens in a cell line derived from retinal tumors in transgenic mice. Invest Ophthalmol Vis Sci 2004, 45:764-768.

57. Ross JA, Kasum CM: Dietary flavonoids: bioavailability, metabolic effects, and safety. Annu Rev Nutr 2002, 22:19-34.

58. Rice-Evans CA, Miller NJ, Paganga G: Structure-antioxidant activity relationships of flavonoids and phenolic acids. Free Radic Biol Med 1996, 20:933-956.

59. Seelinger G, Merfort I, Schempp CM: Anti-oxidant, anti-inflammatory and anti-allergic activities of luteolin. Planta Med 2008, 74:1667-1677.

60. Li N, Venkatesan MI, Miguel A, Kaplan R, Gujuluva C, Alam J, Nel A: Induction of heme oxygenase-1 expression in macrophages by diesel exhaust particle chemicals and quinones via the antioxidant-responsive element. J Immunol 2000, 165:3393-3401.

61. Lim JH, Park HS, Choi JK, Lee IS, Choi HJ: Isoorientin induces Nrf2 pathway-driven antioxidant response through phosphatidylinositol 3kinase signaling. Arch Pharm Res 2007, 30:1590-1598.

62. Singh A, Ling G, Suhasini AN, Zhang P, Yamamoto M, Navas-Acien A, Cosgrove G, Tuder RM, Kensler TW, Watson WH, Biswal S: Nrf2-dependent sulfiredoxin-1 expression protects against cigarette smoke-induced oxidative stress in lungs. Free Radic Biol Med 2009, 46:376-386.

63. Osburn WO, Wakabayashi N, Misra V, Nilles T, Biswal S, Trush MA, Kensler TW: Nrf2 regulates an adaptive response protecting against oxidative damage following diquat-mediated formation of superoxide anion. Arch Biochem Biophys 2006, 454:7-15. 
64. de Vries HE, Witte M, Hondius D, Rozemuller AJ, Drukarch B, Hoozemans J, van Horssen J: Nrf2-induced antioxidant protection: a promising target to counteract ROS-mediated damage in neurodegenerative disease?. Free Radic Biol Med 2008, 45:1375-1383.

65. Harayama T, Shindou H, Ogasawara R, Suwabe A, Shimizu T: Identification of a novel noninflammatory biosynthetic pathway of platelet-activating factor. J Biol Chem 2008, 283:11097-11106.

66. Sheikh AM, Nagai A, Ryu JK, McLarnon JG, Kim SU, Masuda J: Lysophosphatidylcholine induces glial cell activation: role of rho kinase. Glia 2009, 57:898-907.

67. Stuart LM, Bell SA, Stewart CR, Silver JM, Richard J, Goss JL, Tseng AA, Zhang A, El Khoury JB, Moore KJ: CD36 signals to the actin cytoskeleton and regulates microglial migration via a p130Cas complex. J Biol Chem 2007, 282:27392-27401

68. Martin CB, Ingersoll SA, Martin BK: Transcriptional control of the C3a receptor gene in glial cells: Dependence upon AP-1 but not Ets. Mol Immunol 2007, 44:703-712.

69. Nguyen $H$, Teskey L, Lin R, Hiscott J: Identification of the secretory leukocyte protease inhibitor (SLPI) as a target of IRF-1 regulation. Oncogene 1999, 18:5455-5463.

70. Ramsauer K, Farlik M, Zupkovitz G, Seiser C, Kroger A, Hauser H, Decker T: Distinct modes of action applied by transcription factors STAT1 and IRF1 to initiate transcription of the IFN-gamma-inducible gbp2 gene. Proc Natl Acad Sci USA 2007, 104:2849-2854.

71. Zauberman A, Lapter S, Zipori D: Smad proteins suppress CCAAT/ enhancer-binding protein (C/EBP) beta- and STAT3-mediated transcriptional activation of the haptoglobin promoter. J Biol Chem 2001, 276:24719-24725.

72. White CA, McCombe PA, Pender MP: Microglia are more susceptible than macrophages to apoptosis in the central nervous system in experimental autoimmune encephalomyelitis through a mechanism not involving Fas (CD95). Int Immunol 1998, 10:935-941.

73. Streit WJ, Braak H, Xue QS, Bechmann I: Dystrophic (senescent) rather than activated microglial cells are associated with tau pathology and likely precede neurodegeneration in Alzheimer's disease. Acta Neuropathol 2009, 118:475-485.

doi:10.1186/1742-2094-7-3

Cite this article as: Dirscherl et al:: Luteolin triggers global changes in the microglial transcriptome leading to a unique anti-inflammatory and neuroprotective phenotype. Journal of Neuroinflammation 2010 7:3.

\section{Publish with Bio Med Central and every scientist can read your work free of charge}

"BioMed Central will be the most significant development for disseminating the results of biomedical research in our lifetime. "

Sir Paul Nurse, Cancer Research UK

Your research papers will be:

- available free of charge to the entire biomedical community

- peer reviewed and published immediately upon acceptance

- cited in PubMed and archived on PubMed Central

- yours - you keep the copyright 